\title{
IMPROVING THE EFFICIENCY OF OUTSOURCING SERVICES IN THE BULGARIAN ARMED FORCES
}

\author{
Nikolay STEFANOV \\ "Vasil Levski" National Military University, Veliko Tarnovo, Bulgaria \\ niki.s@abv.bg
}

\begin{abstract}
The outsourcing services in the sphere of armed forces could be introduced as a dynamic management strategy. The aim of this strategy is to relocate the non-functional activities to external contractors, mainly for a long period of time, in order to realise savings, increase the specialisation and improve the quality of the delivered services.

The ultimate goal is to provide additional resources and time to implement the core specific activities of the organisation. The efficiency of the outsourcing process is directly related to the ability of the military unit to carefully select which activities and services to outsource.

This article analyses the possibilities for increasing the efficiency of outsourcing services in the structures of the Bulgarian Armed Forces.
\end{abstract}

KEYWORDS: Outsourcing services, SWOT analysis, Bulgarian Armed Forces

\section{Introduction}

In economics, outsourcing is widespread and has been successfully used since the early eighties of the 20th century. It aims to reduce bureaucracy, develop entrepreneurship, and enable companies to respond quickly to changing market demands.

Although the main motives for traditional outsourcing are usually focused on economic motivators, outsourcing of military services may involve a mix of economic and military needs.

The terminology dictionary of the Logistics Doctrine, introduced by Ministerial Order No. OX-191/08.03.2013, defines military outsourcing as entrusting non-core activities to private contractors (The Logistics Doctrine, 2013).
The factors contributing to application of outsourcing by the Bulgarian army are as follows:

$>$ the possibility of professionalisation of the armed forces and logistics provided by focusing the attention of the personnel towards the fulfillment of the basic tasks arising from the specifics of the military profession;

efficient use of all available financial resources;

rational use of human capacity, materials, technology, infrastructure and weapons.

Military outsourcing has certain distinctive features that can lead to a number of implications for the operational readiness of the military units (Report on 
the State of Defense and the Armed Forces of the Republic of Bulgaria, 2009). It is striking that unresolved issues, provoked by suddenly emerging events and situations, arise when using external contractors in conducting operations in conflict areas. Hence, the outsourcing contracts in crisis operations need to be more flexible and different from those concluded in peacetime operations. Many of the issues related to the execution of contracts by external contractors in conflict situations are based on trust, mutual understanding and partnership (Banabakova, Filipov \& Stoyanov, 2017). It is almost impossible to include such characteristics in a standard contract, which leads to the need to draw up a contract that meets all future events.

Successful outsourcing requires excellent knowledge of the capabilities of the military unit and its future tasks. This means that before selecting an outsourcing partner, it is necessary to organise and plan the activities related to the efficient solution for the use of outsourcing services and a comprehensive market survey (Nichev, 2017a).

2. SWOT Analysis of the Possibilities for Increasing the Efficiency of the Outsourcing Services in the Bulgarian Armed Forces

Some researchers, in a number of their publications, look at different aspects of the relationship between providing food for military units' personnel and outsourcing services (Nichev, 2011; Glushkov, 2017a;
Nichev, 2017b). According to P. Glushkov (2017b), "better efficiency of nutrition in the Ministry of Defense could be realized" if account is taken of the possibilities of relocating services to external contractors, i.e. the use of outsourcing services. The practical analyses of the demand and supply of outsourcing services and their application in the sphere of armed forces are sufficient grounds for attempting to answer the questions related to increasing the efficiency of outsourcing services in the Bulgarian Armed Forces. That is why this article presents the developed SWOT using the expert judgment approach. The study of the expert opinions was carried out through an evaluation card, completed by officers from different structures in the Bulgarian Armed Forces, as well as experts in the researched field. The survey included officers from Land Forces, Air Force and Navy units, as well as the Logistics Brigade and the Vasil Levski National Military University.

The evaluation card has four parts:

1. Strengths with 14 evaluation indicators.

2. Weaknesses with 10 evaluation indicators.

3. Options with 6 evaluation indicators.

4. Threats with 5 evaluation indicators.

For each of the indicators, depending on their significance, the experts' evaluations vary from 1 to 5 .

The graphical interpretation of the SWOT analysis is presented in Figures no. $1-\mathrm{A}$ and $\mathrm{B}$.

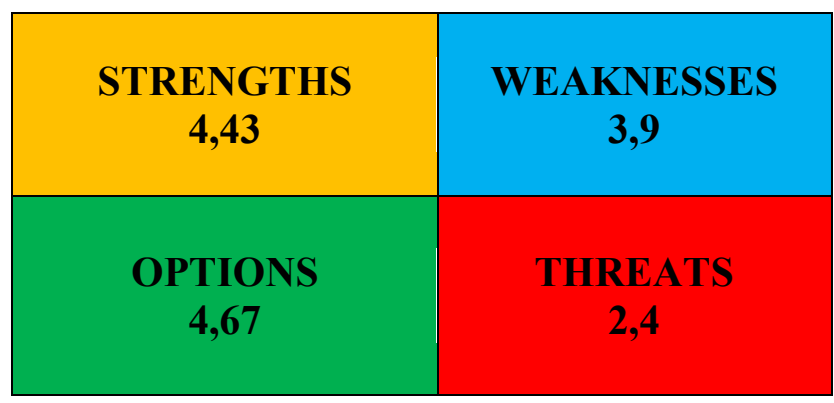

Figure no. 1 A: SWOT analysis of the possibilities for increasing the efficiency of outsourcing services in the Bulgarian Armed Forces 


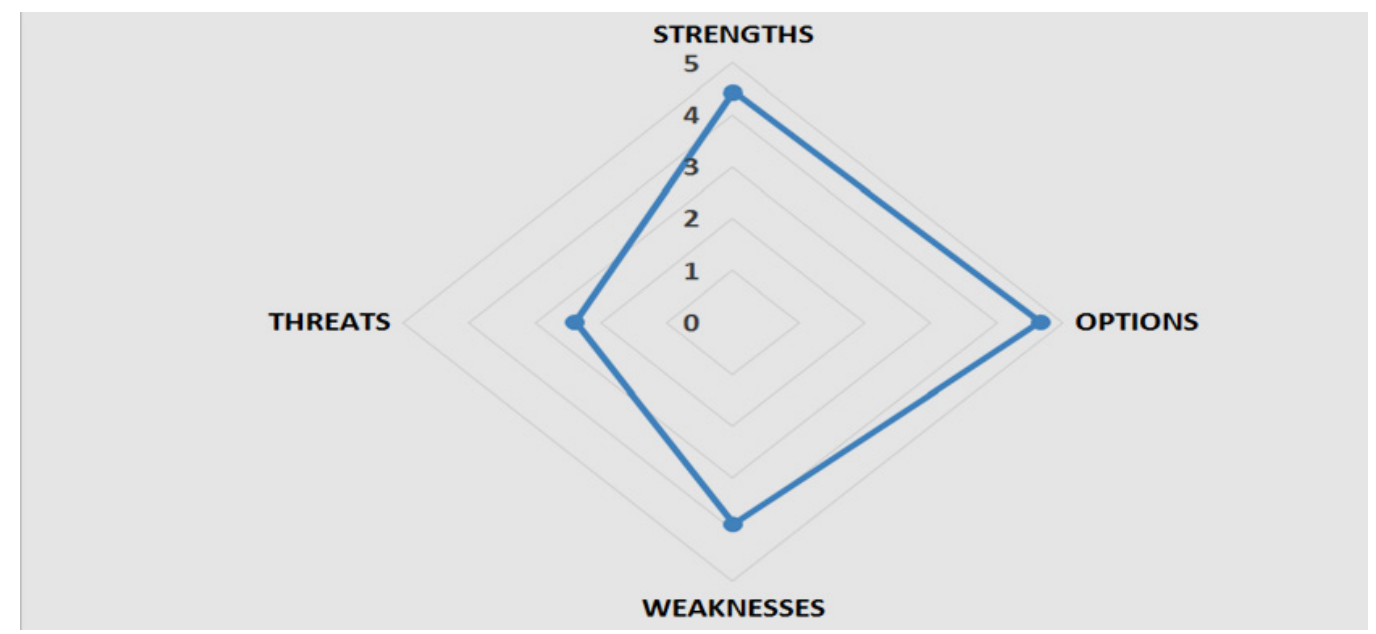

Figure no. 1 B: SWOT analysis of the possibilities for increasing the efficiency of outsourcing services in the Bulgarian Armed Forces

The results from the use of the possibilities for increasing the efficiency of outsourcing services in the Bulgarian Armed Forces also suggest the trends that should be addressed in this respect. This requires:

$\checkmark$ optimisation and improvement of the overall outsourcing process in order to increase and rationalise its positive outcomes;

$\checkmark$ improvement and maintenance of measures for control, analysis and evaluation of the efficiency of the use of outsourcing services in the sphere of the armed forces;

$\checkmark$ study and analysis of the opinion of the military on the positive trends of the use of such services and their exploitation to the fullest extent possible;

$\checkmark$ study and analysis of the opinion of the military about the negative factors influencing the application of this type services and the identification of measures for their elimination.

The greatest attention should be paid to the problems associated with the use of outsourcing services evaluated with 4 or 5 . They are the ones that hinder the increase of efficiency. These are:

$\checkmark$ lack of full control over outsourcing services -5

$\checkmark$ poor knowledge of outsourcing as a strategy in the sphere of the armed forces -4 $\checkmark$ dependence on the outsourcing partner -5

$\checkmark$ lack of skills for analysis and optimisation of the outsourcing services used in the Bulgarian Armed Forces -5

$\checkmark$ problems arising from noncompliance with the contract and the mutual rights and obligations -4

$\checkmark$ missing or insufficient rules for management and control of the efficiency of using outsourcing services -5 .

The presented weaknesses, i.e. problems, could be managed and overcome. However, their reduction and elimination requires targeted work related to the effective management and control of the overall outsourcing process, aimed at updating and enhancing the competence and application of practically proven approaches and models.

The weaknesses, or problems, evaluated with 2 or 3 , are of average significance; these are:

$\checkmark$ low motivation and higher staff turnover -2

$\checkmark$ low communication and coordination with the external contractor -3

$\checkmark$ lack of an efficient strategy and policy in relation to the control of outsourcing contracts -3

$\checkmark$ lack of experience in preparing outsourcing contracts -3 . 
These problems can also be overcome, but although they are less important, they should not be underestimated. The main thing is to take on the role and the positive practice of using outsourcing services for the overall specific activity of the Bulgarian Armed Forces and on this basis to invest in their optimisation and improvement (Figure no. 2).

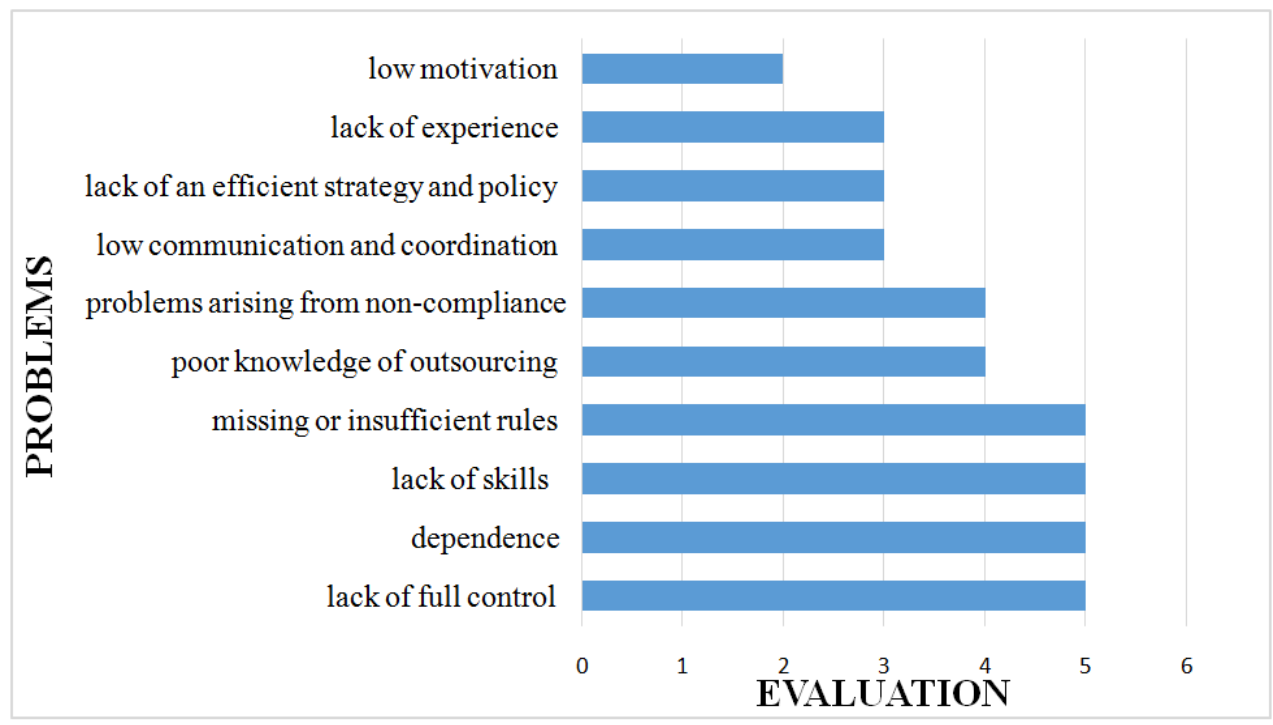

Figure no. 2: Problems related to the increase of the efficiency of outsourcing services in the Bulgarian Armed Forces

The threats which arise from the use of such services in the armed forces should not be underestimated either. An advantage is that the factors which look like threats are of average importance (Figure no. 3):

$\checkmark$ bankruptcy of the external contractor -3

$\checkmark$ insecurity for the employee -1

$\checkmark$ insufficient qualification of the external contractor -3

$\checkmark$ leakage of information -2

$\checkmark$ decrease of the quality of the services offered -3
The units of the armed forces should consider those threats as factors which need to be defined and thoroughly examined. The structures of the Bulgarian Armed Forces, engaged in research, analysis, planning, management and control of outsourcing services, need to identify and exclude the threats through a purposeful and adequate management strategy as they may lead to reduction of the efficiency of the outsourcing process.

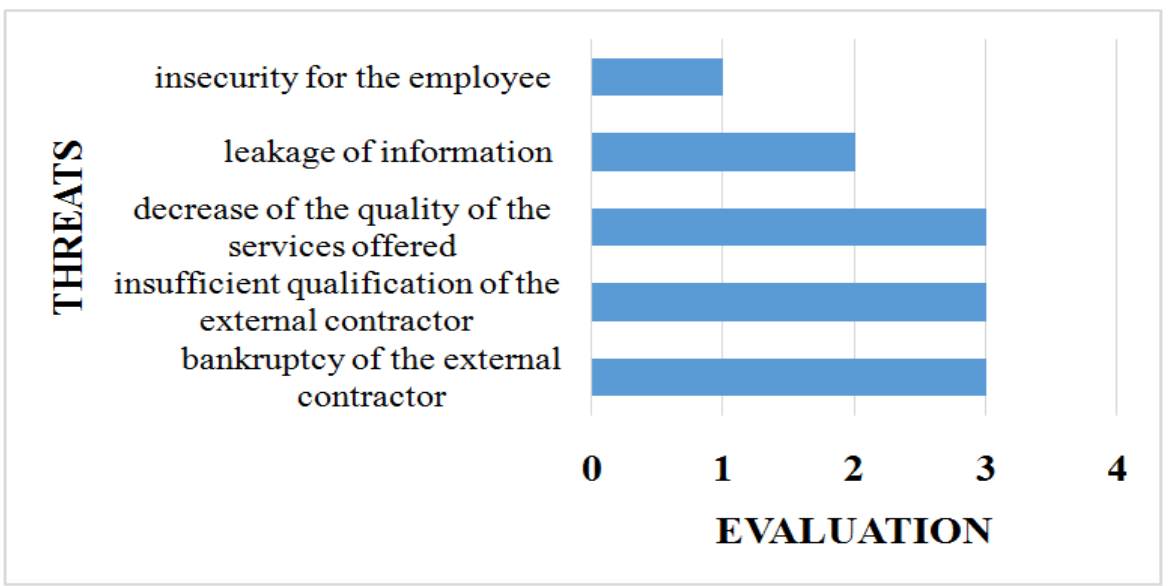

Figure no. 3: Threats related to increasing the efficiency of outsourcing services in the Bulgarian Armed Forces 
Based on the analyses of the application of outsourcing services in the Bulgarian Armed Forces and the possibilities for enhancing their effectiveness, it is advisable to develop and implement an effective strategy and policy in the following trends:

$\checkmark$ research, study and analysis of good practices with regard to the implementation of such services by other NATO member armed forces;

$\checkmark$ analysis and evaluation of each of the options for switching to outsourcing services;

$\checkmark$ identification and evaluation of each of the alternatives with a focus on outsourcing;

$\checkmark$ evaluation of the cost, benefits and risks of each alternative before deciding on the transfer of services;

$\checkmark$ deciding on the use of outsourcing services which will ensure the most favourable positive results for the respective unit with the lowest possible cost and taking into account the budget and price constraints;

$\checkmark$ identification and evaluation of the key indicators for increasing the efficiency of the outsourcing process;

$\checkmark$ selection and formulation of the strategy which is most appropriate for the military unit in order to increase the efficiency of the intended outsourcing services;

$\checkmark$ performing a systematic and comprehensive control, analysis and evaluation of the results of the outsourcing services used, identifying the differences from the adopted specifications and rules in the contract, as well as from the strategy and activity of the unit, discovering the reasons for these deviations and making corrective decisions on the implementation of the contract in accordance with each specific situation.
The results of the analysis of the possibilities for increasing the efficiency of the outsourcing services in the structures of the Bulgarian Armed Forces show positive trends and the desire to use them. The weaknesses identified in the SWOT analysis are can be managed and overcome, but they require systematic study, analysis, evaluation and elimination by the governing bodies of the armed forces.

\section{Conclusion}

The application of outsourcing services by the armed forces, despite the risks inherent in its use, is a promising tool for cutting defense costs (Headquarters, 2011).

The applicability of outsourcing in the sphere of defense "allows soldiers to focus on the implementation of their specific tasks related to the combat preparation of the military units" (Nichev, 2017a).

The research and analysis performed lead to the conclusion that the selection of the most appropriate supplier, the preliminary definition of the financial frames of the contract, and the well-timed and well-judged communication with the supplier are of the utmost importance in order to keep the military unit as a client.

The main goals of making a decision to switch to outsourcing are not only to increase the efficiency and effectiveness of military logistics capabilities, but also to perform defense tasks with reduced workload and at a minimum cost.

The choice of an outsourcing solution of a single activity should be based on the analysis of the advantages and drawbacks of using outsourcing, the assessment of the costs of the different performance options, "the potential risks of its use, and the objective comparison of the alternatives on the basis of an acceptable balance between quality and cost" (Stefanov, 2017a). 


\section{REFERENCES}

Banabakova, V., Filipov, S., \& Stoyanov, S. (2017). State and Problems of Warehousing of the Bulgarian Armed Forces, The $23^{\text {rd }}$ International Conference KnowledgeBased Organization, Volume XXIII, No. 2, 9-15.

Glushkov, P. (2017a). A Study of Nutrition and the Nutritional Status of Servicemen, Assessed on the Basis of Anthropometric Indicators, The $23^{\text {rd }}$ International Conference Knowledge-Based Organization, Volume XXIII, No. 2, 298-302.

Glushkov, P. (2017b). Use of Linear Optimization Model in Defining the New Standards for the Preparation of Food for Servicemen During the Preparation for Participation in Peacekeeping Operations, The $23^{\text {rd }}$ International Conference Knowledge-Based Organization, Volume XXIII, No. 2, 65-70.

Headquarters, Department of the Army. (2011). Operational Contract Support Tactics, Techniques, and Procedures, available at: https:/fas.org/irp/doddir/army/attp4-10.pdf

Logistics Doctrine. (2013). National Publication of the Armed Forces Republic Bulgaria NP - 4, Sofia, BG: Military Publishing House.

Nichev, N. (2017b). Possibility for Improving the Planning of the Needs for Food for Bulgarian Army Units When Participating in Humanitarian Operations, Revista Academiei Fortelor Terestre, Vol. XXII, Nr. 1(85), 18-24.

Nichev, N. (2011). Theoretical Foundations of Military Logistics - Organization of Logistical Support, V. Tarnovo, BG: Vasil Levski National Military University.

Nichev, N. (2017a). Risk Management in the Decision Making Process Concerning the Use of Outsourcing Services in the Bulgarian Armed Forces, The $23^{\text {rd }}$ International conference Knowledge-Based Organization, Volume XXIII, No. 2, 405-410.

Report on the State of Defense and the Armed Forces of the Republic of Bulgaria. (2009). Sofia, BG: Council of Ministers of the Republic of Bulgaria.

Stefanov, N. (2017a). Analysis of the Use of Outsourcing Services for Maintenance and Repair of the Equipment and Armament Available in the Structures of the Bulgarian Armed Forces, The $23^{\text {rd }}$ International Conference Knowledge-Based Organization, Volume XXIII, No. $1,467-472$. 